\title{
Transplantation of EPCs overexpressing PDGFR- $\beta$ promotes vascular repair in the early phase after vascular injury
}

Hang Wang ${ }^{1 \dagger}$, Yang-Guang Yin ${ }^{2 \dagger}$, Hao Huang ${ }^{3}$, Xiao-Hui Zhao ${ }^{4}$, Jie Yu ${ }^{4}$, Qiang Wang ${ }^{4}$, Wei $\mathrm{Li}^{4}$, Ke-Yin Cai ${ }^{1}$ and Shi-Fang Ding ${ }^{5^{*}}$

\begin{abstract}
Background: Endothelial progenitor cells (EPCS) play important roles in the regeneration of the vascular endothelial cells (ECS). Platelet-derived growth factor receptor (PDGFR)- $\beta$ is known to contribute to proliferation, migration, and angiogenesis of EPCs, this study aims to investigate effects of transplantation of EPCs overexpressing PDGFR- $\beta$ on vascular regeneration.

Methods: We transplanted genetically modified EPCs overexpressing PDGFR- $\beta$ into a mouse model with carotid artery injury. After 3 days of EPCs transplantation, the enhanced green fluorescent protein (EGFP)-expressing cells were found at the injury site and the lining of the lumen by laser scanning confocal microscope (LSCM). At 4, 7, and 14 days of the carotid artery injury, reendothelialization was evaluated by Evans Blue staining. Neointima formation was evaluated at day 14 with hematoxylin and eosin (HE) staining by calculating the neointimal area, medial area, and neointimal/media (NI/M) ratio. Intimal cell apoptosis was evaluated using TUNEL assay. Then we tested whether PDGF-BB-induced VSMC migration and PDGF-BB's function in reducing VSMC apoptosis can be attenuated by EPCs overexpressing PDGFR- $\beta$ in a transwell co-culture system.
\end{abstract}

Results: Our results showed that EPCs overexpressing PDGFR- $\beta$ accelerates reendothelialization and mitigates neointimal formation at 14 days after injury. Moreover, we found that there is great possibility that EPCs overexpressing PDGFR- $\beta$ enhanc VSMC apoptosis and suppress VSMC migration by competitive consumption of PDGF-BB in the early phase after carotid artery injury in mice.

Conclusions: We report the first in vivo and in vitro evidence that transplantation of genetically modified EPC can have a combined effect of both amplifying the reendothelialization capacity of EPCs and inhibiting neointima formation so as to facilitate better inhibition of adverse remodeling after vascular injury.

Keywords: EPCS, PDGFR- $\beta$, Reendothelialization, Neointima, Gene therapy

\section{Background}

The normal arterial vessel wall is mostly composed of endothelial cells (ECs), vascular smooth muscle cells (VSMCs), and macrophages. Endothelial impairment is believed to be a major contributor to atherosclerosis and restenosis after percutaneous coronary intervention (PCI) $[1,2]$. Reendothelialization can effectively inhibit VSMC

\footnotetext{
* Correspondence: dsfmd2015@163.com

${ }^{\dagger}$ Equal contributors

${ }^{5}$ Institute of Cardiovascular Science, Wuhan General Hospital of Guangzhou Military Command, Wuhan 430070, China

Full list of author information is available at the end of the article
}

migration and proliferation and decrease neointimal thickening [3]. Therefore, acceleration of reendothelialization is of special interest with regard to reducing neointima formation to prevent postangioplasty restenosis and development of atherosclerosis.

Endothelial progenitor cells (EPCs) include cells in multiple stages from mother cells to mature ECs. Both early EPCs that can repair the blood vessels and the late EPCs that have strong proliferation ability are involved in angiogenesis. Indeed, the numbers of EPCs in a patient with atherosclerotic vascular disease, who needs endothelial repair, are much lower 
than that in a normal person [4-6]. Recently, several studies showed that EPCs can be recruited to the sites of endothelial injury, be differentiated into mature ECs, and can play important roles in reendothelialization after vascular injury [7-10]. Platelet-derived growth factor (PDGF) can enhance VSMC function and injury-induced neointima formation. PDGF-BB gene knockout mice show pathological defects such as heart and blood vessel dilations, proving that PDGF-BB plays a vital role in the establishment of the circulatory system in the body [11]. Recently, it was reported that PDGF-BB was locally produced by injured arteries, and it contributed to the promotion of migration, proliferation, and neointima formation of local VSMCs for participation in vascular repair/ remodeling in human and animal vascular injury models [12]. However, inhibition of PDGF-BB signaling has been shown to reduce neointima formation and inhibit vascular repair/remodeling after angioplasty [13-15]. Our previous study also showed that overexpression of PDGF-receptor (PDGFR)- $\beta$ promoted PDGF-BB-induced proliferation, migration, and angiogenesis of EPCs [16].

Based on known knowledge regarding PDGF-BB and PDGFR- $\beta$ on the biological functions of VSMCs and EPCs, we propose that EPCs overexpressing PDGFR- $\beta$ may have effects on reendothelialization during arterial repairment after injury. To test this, we transplanted genetically modified EPCs overexpressing PDGFR- $\beta$ into a mouse model with carotid artery injury and evaluated whether locally released PDGF-BB can stimulate homing of the transplanted EPCs to the site of endothelial injury and improve their biological functions. We further investigated whether the homed EPCs overexpressing PDGFR- $\beta$ can compete for the locally produced PDGF-BB produced by injured arteries with the VSMCs to inhibit the local VSMC migration, proliferation, and neointima formation. Our results showed that transplantation of genetically modified EPC may have a combined effect of both amplifying the reendothelialization capacity of EPCs for repairing injured arteries as well as inhibiting the capacity of EPCs in neointima formation so as to facilitate better inhibition of adverse remodeling after vascular injury.

\section{Methods}

\section{Animals and protocols}

All procedures were performed in compliance with the Ethic Committee of Third Military Medical University and the National Institute of Health Guide for the Care and Use of Laboratory. Animals Male C57BL/6 mice (weight: $25-30 \mathrm{~g}$, age: 6-8 weeks) were obtained from the Laboratory Animal Center at the Third
Military Medical University (Chongqing, China). Mice were firstly anaesthetized by $40 \mathrm{mg} / \mathrm{kg}$ sodium pentobarbital (Sigma-Aldrich, St Lois, MO, USA) via iintraperitoneal (IP) injection. The extent of anaesthesia was assessed by mouse's reaction to the toe pinching during the splenectomy or the carotid artery injury surgery. Then they received $3 \mathrm{mg} / \mathrm{kg}$ ketorolac tromethamine (Newtime, Shandong, China) by per os $(\mathrm{PO})$ to minimize the postoperative pain. At last all mice were euthanized by IP injection of $240 \mathrm{mg} / \mathrm{kg}$ sodium pentobarbital.

\section{Splenectomy}

Splenectomy was performed as described in our previous study [17]. Vessels of the mice were carefully ligated using 6-0 silk ligatures via a lateral incision of the left abdomen, followed by ablation of the spleen. The abdomen was immediately closed layer by layer with single sutures using 6-0 silk. The mice were allowed to recover for 14 days after which the carotid arterial injury was induced.

\section{EPC culturing and characterization}

Culturing and characterization of mouse spleenderived EPCs was performed as described previously $[16,18]$. To determine the endothelial phenotype of EPCs, the cells were incubated with $2.4 \mu \mathrm{g} / \mathrm{mL}$ acLDL-DiI (Invitrogen, CA, USA) for $4 \mathrm{~h}$, fixed with $4 \%$ paraformaldehyde (PFA), and then incubated with $10 \mu \mathrm{g} / \mathrm{mL}$ FITC-UEA-1 (Sigma-Aldrich, St. Louis, MO, USA) for $1 \mathrm{~h}$. The cells positive for both acLDL-DiI and UEA-1 were identified as differentiating EPCs. In addition, the phenotypes of EPCs were evaluated by flow cytometry $(\mathrm{FCM})$. Cells $(1 \times 106)$ were incubated with the following monoclonal antibodies: PE-conjugated anti-VEGFR-2 (eBiosciences, San Diego, CA, USA), FITC-conjugated anti-Sca-1 (abCAM, Cambridge, MA, USA), or their corresponding isotype controls (eBiosciences).

\section{EPCs gene transfer}

The plasmids pEGFP-N2 and pEGFP-N2-PDGFR- $\beta$ were kindly provided by $\mathrm{Dr}$. Shangcheng $\mathrm{Xu}$ at the Third Military Medical University. Transfection was performed, as described previously [16], with the Lipofectamine $^{\mathrm{rw}} 2000$ reagent (Invitrogen, Shanghai, China), according to the manufacturer's instruction. The EPCs of the pEGFP-N2 or pEGFP-N2-PDGFR- $\beta$ groups were collected $24 \mathrm{~h}$ after transfection.

\section{VSMC culturing and characterization}

VSMCs were isolated from the thoracic aorta of mice through explantation and cultured in Dulbecco's Modified Eagle Medium: nutrient mixture F-12 
(DMEM/F-12) culture medium (Gibco BRL, NY, USA) supplemented with $20 \%$ fetal calf serum (FCS, Gibco BRL, NY, USA), $100 \mathrm{U} / \mathrm{mL}$ penicillin, and 100 $\mathrm{U} / \mathrm{mL}$ streptomycin. Cells were kept at $37{ }^{\circ} \mathrm{C}$ in a $5 \%$ $\mathrm{CO}_{2}$ atmosphere. Cultures were confirmed by smooth muscle $\alpha$-actin (SM $\alpha$ A, NeoMarkers, CA, USA). Cells from 3 to 6 passages were used for all experiments.

\section{Carotid artery injury model and EPC transplantation}

Injury of carotid artery was induced 14 days after splenectomy, as described in our previous study [19]. Briefly, the bifurcation of the left carotid artery was exposed through a midline incision on the ventral side of the neck. A 6-0 silk slipknot was placed around the common carotid artery and the internal carotid artery to block their blood flow. Two ligatures were placed proximally and distally around the external carotid artery, and the distal ligature was then tied off. A tailored hook made from a syringe $(1 \mathrm{~mL})$ was used to place the silk around the external and the internal carotid arteries. An incision was made between the two ligatures to introduce the denudation device. The tailored flexible wire (0.014-in. diameter, the tip of the wire was relatively thinner) was introduced into the common carotid artery. The endothelium was denuded by passing the wire back and forth through the vessel three times. After removal of the wire, the proximal ligature of the external carotid artery was tied off. The slipknots were removed, and the blood flow was restored. The skin incision was sutured with 6-0 silk. Then, the mice were administered $200 \mu \mathrm{L}$ saline alone or $200 \mu \mathrm{L}$ saline containing enhanced green fluorescent protein (EGFP)-labeled EPCs $\left(1 \times 10^{6}\right)$ or EPCs overexpressing PDGFR- $\beta\left(1 \times 10^{6}\right)$ via tail vein injection directly after endothelial injury of the carotid artery and again after $24 \mathrm{~h}$.

\section{EPC tracing in vivo}

To observe whether the transfected EPCs were capable of homing to the site of injury, labeled pEGFPN2-EPCs and pEGFP-N2- PDGFR- $\beta$-EPCs $\left(1 \times 10^{6}\right)$ were incubated with $2.4 \mu \mathrm{g} / \mathrm{ml}$ acLDL-DiI (Invitrogen, CA, USA) for $1 \mathrm{~h}$. Then the cells were washed with PBS 3 times and injected into the mice' tail vein in $200 \mu \mathrm{L}$ saline after induction of arterial injury and again after 24 h. 7 days later, EPC tracking and immunohistochemistry were performed. Images of the stained cells were obtained by a fluorescence microscope (Leica).

RNA extraction and semi-quantitative reverse transcription-polymerase chain reaction (RT-PCR)

Total RNA was extracted from the arteries by using RNAout (Tianenze Biotech, Beijing, China), and the cDNA was obtained through RT-PCR with the PrimeScript ${ }^{\text {mix }}$ RT Reagent Kit (Takara, Biotechnology, Dalian, China) by using total RNA as a template, followed by amplification. The primers used were as follows: PDGFR- $\beta$ (sense) $5^{\prime}$ CCGGCGCTGGCGAGTTAGTTT-3', (antisense) 5' ACACCTACTTTTGAGGTCTCTGCAGG-3'; product length 296 bp. PDGF-BB (sense) 5'-TGCTGAGCGACCACTCCATC-3', (antisense) 5'-TGTGCTCGGGTCAT GTTCAAG-3'; product length $109 \mathrm{bp}$. Glyceraldehyde 3phosphate dehydrogenase (GAPDH) (sense) 5' - AAC TTTGGCATTGTGGAAGGGCTC-3', (antisense) $5^{\prime}$ - AC CCTGTTGCTGTAGCCGTATTCA-3'; product length 473 bp. All primers were obtained from Invitrogen (Shanghai, China).

\section{Western blotting}

The protein concentration of tissue lysates was estimated by the Bradford method, and the proteins were transferred onto polyvinylidene fluoride (PVDF) membranes. The membranes were blocked with $5 \%$ non-fat milk, probed with anti-PDGFR- $\beta$ (Abcam, USA), anti-PDGF-BB (Santa Cruz Biotechnology, USA), and anti-GAPDH (Cell Signaling Biotechnology, Beverly, MA, USA), followed by staining with horseradish peroxidase-coupled secondary antibodies. The protein bands were visualized by enhanced chemiluminescence (Amersham Pharmacia Biotech, UK) and quantified by using the Quantity One software (Bio-Rad, Hercules, USA).

\section{Immunofluorescence}

Before and 7 days after the carotid artery injury, the carotid arteries were snap-frozen in liquid nitrogen in optimal cutting temperature (OCT)-embedding medium and stored at $-80{ }^{\circ} \mathrm{C}$. Six cross-sections were cut $(5-\mu \mathrm{m}$ thickness) from the approximate middle portion of the artery and used for the detection of PDGF-BB by immunofluorescence. For fluorescence staining, the sections were first incubated with an anti-PDGF-BB primary $\mathrm{mAb}(1: 100)$ and then with a FITC-labeled secondary antibody (Beyotime, Shanghai, China). Images of the sections were obtained by a laser scanning confocal microscope (LSCM; Leica).

\section{Measurement of reendothelialization}

After 4, 7, and 14 days of the carotid artery injury, endothelial regeneration was evaluated by staining the denuded areas by injecting $200 \mu \mathrm{L}$ of $5 \%$ Evans Blue dye with saline via the tail vein into the heart. The left common carotid artery was then harvested $5 \mathrm{~mm}$ away from the carotid bifurcation. The reendothelialized area appeared white in color (unstained), whereas the non-endothelialized lesions appeared blue (stained). The unstained-areas (in white) and the total carotid artery areas were measured. The ratio of 
reendothelialized areas (unstained area) versus the total carotid artery area were calculated.

\section{Assessment of neointimal and medial areas}

For histological analysis, hematoxylin and eosin (HE) staining was performed, according to the standard protocols; three sections taken from the middle portion of each artery, 14 days after the carotid artery injury, were examined; and the neointimal area, medial area, and neointima/media (NI/M) ratio were calculated.

\section{Apoptosis assay in the intima}

Seven days after the carotid artery injury, the carotid arteries were snap-frozen in liquid nitrogen in OCTembedding medium and stored at $-80{ }^{\circ} \mathrm{C}$. Six crosssections $(5-\mu \mathrm{m}$ thick), cut from the approximate middle portion of the artery, were used for the detection of intimal apoptotic cells by immunofluorescence for terminal deoxynucleotidyl transferase dUTP nick-end labeling (TUNEL) by using the in situ Cell Death Detection Kit (Roche), according to the manufacturer's instructions, and then SmaA staining of VSMCs, DAPI staining of the nuclei of cells was performed. After the fluorescence staining, the numbers of TUNEL-positive and-negative nuclei were counted in five different high-power fields (HPFs) in each section under the LSCM. Apoptosis activity was expressed in terms of TUNEL-labeling index, calculated by dividing the positively labeled cells by the total cell number.

\section{VSMCs and EPCs co-culture}

For the settlement of the VSMC/EPC system, VSMCs were seeded on Transwell filters $(4 \mu \mathrm{m}$ pores or $8 \mu \mathrm{m}$ pores, Corning Costar, USA). A total of $2.5 \times$ $10^{5}$ EPCs were cultured and were transfected in a separate well, on the lower chamber of the system. After both types of cells reached confluency, the inserts with VSMCs were added to the wells where EPCs were cultured (resulting). Three groups of cells were VSMCs and EPCs co-cultured (Fig. 1): (1) control group: no cells were cultured on the lower chamber of the system; (2) pEGFP-N2 group : EPCs with the plasmid pEGFP-N2 transfection were cultured on the lower chamber of the system; (3) pEGFP-N2-PDGFR- $\beta$ group : EPCs with the plasmid pEGFP-N2-PDGFR- $\beta$ transfection were cultured on the lower chamber of the system.

\section{VSMC migration assay}

The co-culture migration assay was examined using the VSMC/EPC system containing $8 \mu \mathrm{m}$ polycarbonate filter inserts in 24-well plates. Three groups of cells were filled in various concentrations $(0,20,40$,

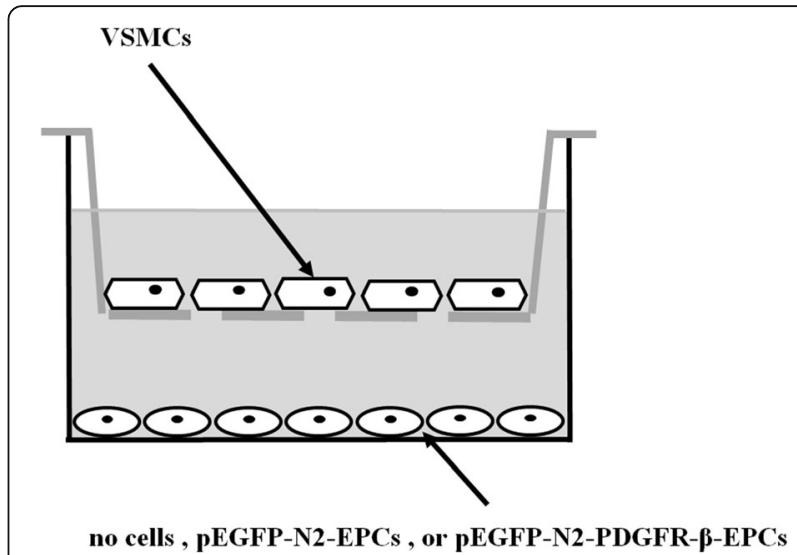

Fig. 1 Illustration of the transwell co-culture system. The transwell consists of two chambers separated by a porous membrane. The VSMCs were placed on the membrane of the upper chamber while no cells, EPCs with the plasmid pEGFP-N2 transfection, or EPCs with the plasmid pEGFP-N2-PDGFR- $\beta$ transfection were placed on the bottom of the lower chamber, respectively

60, or $80 \mathrm{ng} / \mathrm{mL}$ ) PDGF-BB respectively. After $12 \mathrm{~h}$ in culture, VSMCs on the bottom of the Transwell membrane were fixed with $4 \%$ PFA at $37{ }^{\circ} \mathrm{C}$ for $20 \mathrm{~min}$ and stained with $1 \%$ crystal violet at $37{ }^{\circ} \mathrm{C}$ for $5 \mathrm{~min}$. The number of migrating cells on the bottom of the Transwell in 5 randomly HPFs $(\times 200)$ was counted manually. Results were representative of three independent experiments.

\section{VSMC apoptosis assay}

The co-culture apoptosis assay was identified by immunofluorescence for TUNEL by using the in situ Cell Death Detection Kit (Roche, USA), according to the manufacturer's instructions. Briefly, the VSMC/ EPC system containing $4 \mu \mathrm{m}$ polycarbonate filter inserts in 24-well plates were used. Three groups of cells were treated with various concentrations $(0,20$, 40, 60, or $80 \mathrm{ng} / \mathrm{mL}$ ) PDGF-BB in DMEM/F-12 with $1 \%$ FCS (apoptotic condition) for $72 \mathrm{~h}$. VSMCs were fixed in $4 \%$ PFA for $20 \mathrm{~min}$ and then treated with permeabilization solution $(0.2 \%$ Triton X-100 solution in PBS) for $5 \mathrm{~min}$ at room temperature. Labeling reactions were performed with $100 \mu \mathrm{L}$ of reaction buffer for $60 \mathrm{~min}$ at $37{ }^{\circ} \mathrm{C}$ in a in the dark. DAPI staining of the nuclei of VSMCs was performed. After the fluorescence staining, the numbers of TUNELpositive and-negative nuclei were counted in five HPFs $(\times 200)$. Results were representative of three independent experiments. The TUNEL-labeling index was counted manually.

\section{Statistical analysis}

Data from independent experiments were expressed as mean \pm standard deviation (SD). Statistical analyses were 
performed with the SPSS 13.0 software (SPSS Inc, Chicago, USA). Comparisons between the groups were performed by two-tailed Student's $t$-test or analysis of variance (ANOVA). Comparisons between multiple groups were tested by Multi-Way ANOVA. $P<0.05$ was considered statistically significant.

\section{Results}

\section{Overexpression of PDGFR- $\beta$ in transfected EPCs}

EPCs were transfected with either pEGFP-N2 or pEGFPN2-PDGFR- $\beta$. After 10 days of transfection, the mRNA level of PDGFR- $\beta$ in the pEGFP-N2-PDGFR- $\beta$ group $(0.38 \pm 0.02)$ was significantly increased as compared to that in the non-transfected group $(0.24 \pm 0.03, p<0.05)$ or the pEGFP-N2 group $(0.23 \pm 0.04, p<0.05)$, as determined by semi-quantitative RT-PCR (Fig. 2a). Similarly, significantly increased protein level of PDGFR- $\beta$ was also found in the pEGFP-N2-PDGFR- $\beta$ group (1.30 \pm $0.41)$ compared to that in the non-transfected group $(0.60 \pm 0.16, p<0.05)$ and the pEGFP-N2 group $(0.63 \pm$ $0.26, p<0.05)$, as determined by western blotting (Fig. 2b). Our results showed that this overexpression was maintained for at least 10 days.

\section{Expression of PDGF-BB after wire-mediated carotid artery injury in mice}

Localization of the PDGF-BB in injured vessels was investigated by immunofluorescence. PDGF-BB was rarely observed in uninjured carotids (Fig. 3a), but observed in the intima of local injured carotids at day 7 (Fig. 3b).
We analyzed the PDGF-BB expression during vascular injury following wire-mediated carotid artery injury in mice. As shown in Fig. 3c, the PDGF-BB mRNA expression was detected at low levels in uninjured control arteries $(0 \mathrm{~h})$, and started reducing rapidly at $6 \mathrm{~h}$ (3.51-fold). However, the PDGF-BB mRNA level was significantly enhanced at day 7 (3.80-fold) after the vascular injury, followed by a gradual decline at day 14 (1.67-fold).

The PDGF-BB protein expression was assessed by western blotting. The protein level started reducing rapidly at $6 \mathrm{~h}$ (7.80-fold) and $12 \mathrm{~h}$ (2.82-fold). However, the level began increasing gradually at day 2 (2.67-fold), with significant enhancement at day 7 (4.26-fold; Fig. 3d).

\section{Labeled EPCs were observed in injured artery}

After 7 days of EPC transplantation, acLDL-DiIlabeled EPCs were identified as red fluorescence cells (Fig. 4a, b). Labeled cells were seen lining the lumen that co-stained for endothelial markers FITC-UEA-1. No acLDL-DiI-labeled cells were identified in uninjured control arteries (data not shown).

\section{Transplantation of EPCs overexpressing PDGFR- $\beta$ pro- moted reendothelialization}

To investigate whether PDGFR- $\beta$ overexpression could accelerate reendothelialization, Evans Blue staining was performed (Fig. 5a). At day 4, the reendothelialized area in the pEGFP-N2-PDGFR- $\beta$-EPCs transplanted arteries $(17.76 \pm 3.35 \%)$ was significantly larger than in the saline control group $(8.83 \pm 3.16 \%, p<0.01)$ but
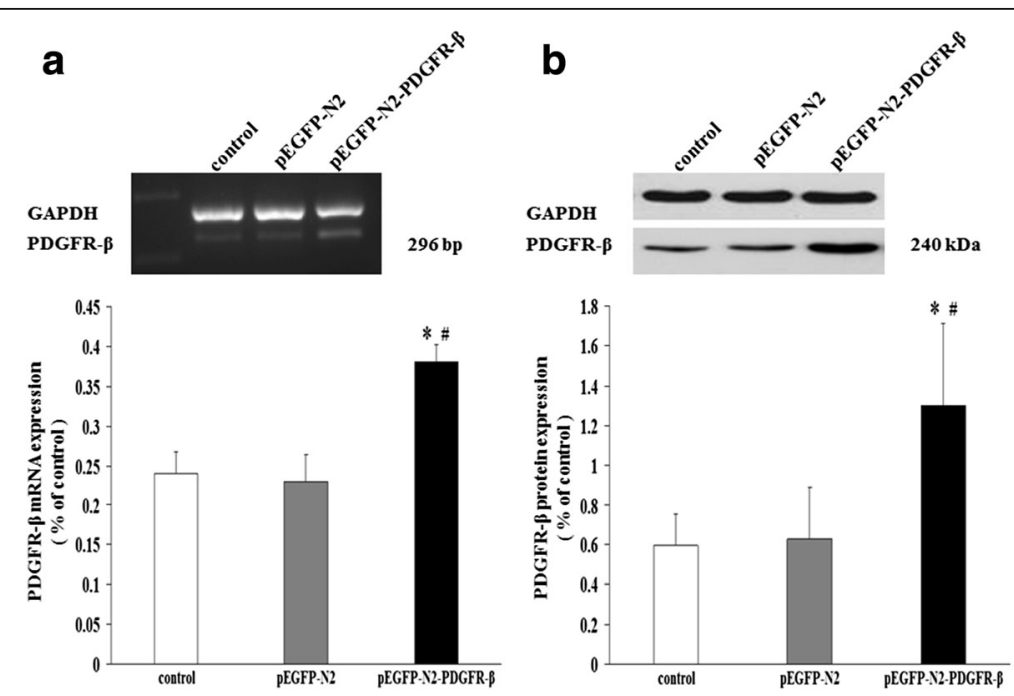

Fig. 2 Overexpression of PDGFR- $\beta$ in transfected EPCs. At 10 days after transfection, PDGFR- $\beta$ mRNA level (a) and protein levels (b) in the pEGFPN2-PDGFR- $\beta$ group were significantly higher than those in the control group and pEGFP-N2 group. ${ }^{*} P<0.05$ vs. control or ${ }^{\#} P<0.05$ vs. pEGFP-N2 ( $n=3$ ) 

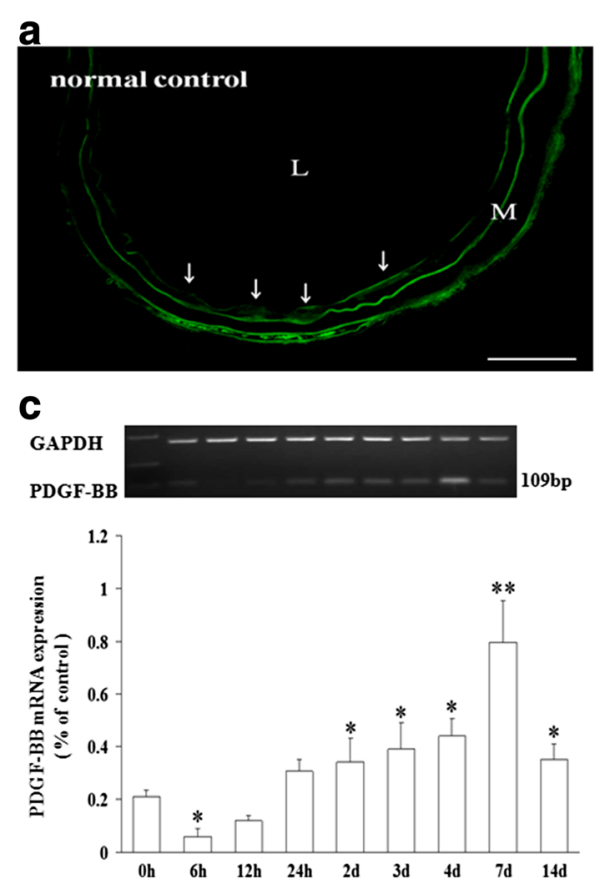

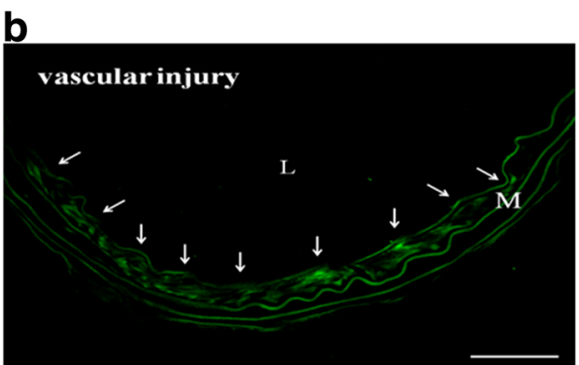

d
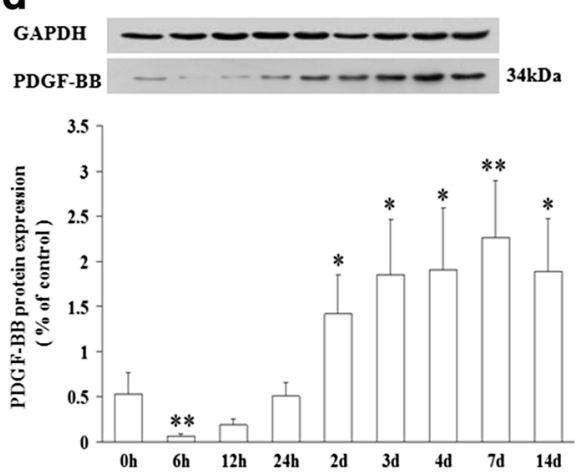

Fig. 3 Comparison of expression of PDGF-BB in normal and vascular injured mice. Arrows indicate immunofluorescence staining for PDGF-BB (green) in normal (a) and wire-mediated carotid artery injury mice (b). c Semi-quantitative RT-PCR revealed that PDGF-BB was significantly enhanced at day 7. d Top: Representative images from western blotting. Bottom: Protein level of PDGF-BB, as assessed by densitometric analysis. ${ }^{*} P<0.05$ vs. 0 h; ${ }^{* *} P<0.01$ vs. 0 h $(n=3)$. L, lumen; M, media. Scale bar $=50 \mu \mathrm{m}$

was not significantly larger $(P>0.05)$ than that in the pEGFP-N2-EPCs transplanted arteries $(16.56 \pm 4.46 \%$; Fig. $5 \mathrm{~b})$. At day 7 , the reendothelialized area in the pEGFP-N2-PDGFR- $\beta$-EPCs transplanted arteries $(58.55 \pm$ $7.17 \%)$ was significantly larger than that in the pEGFPN2-EPCs transplanted arteries $(48.62 \pm 4.55 \% ; p<0.05$; Fig. $5 \mathrm{~b})$ and that in the saline control group $(29.15 \pm$ $7.07 \%, p<0.01)$. At day 14 , the reendothelialized area in the pEGFP-N2-PDGFR- $\beta$-EPCs transplanted arteries
$(76.41 \pm 10.16 \%)$ was significantly larger than that in the pEGFP-N2-EPCs transplanted arteries (53.00 \pm $7.98 \%, p<0.01)$ and that in the saline control group $(34.6 \pm 6.06 \%, p<0.01)$. These results demonstrate that reendothelialization of injured carotid arteries is promoted by EPC transplantation and further enhanced by transplantation with EPCs overexpressing PDGFR- $\beta$ at days 7 and 14 after wire-mediated carotid artery injury.

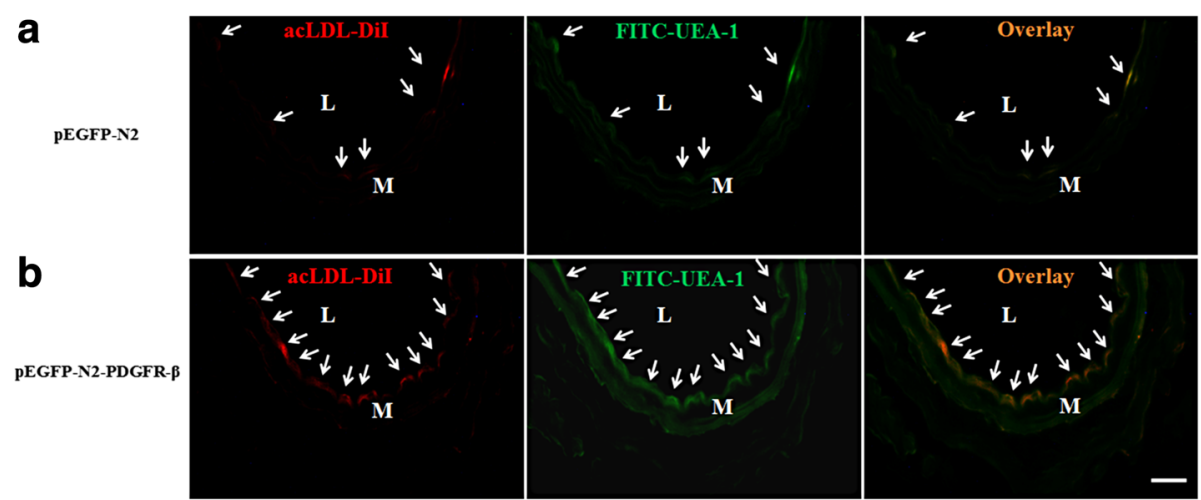

Fig. 4 EPCs tracing in vivo. a Labeled pEGFP-N2-EPCs and $\mathbf{b}$ pEGFP-N2- PDGFR- $\beta$-EPCs were injected into the mice after vascular injury and attached to the vascular injury site on day 7. Arrows indicate EPCS $(n=5)$. L, lumen; M, media. Scale bar $=50 \mu m$ 


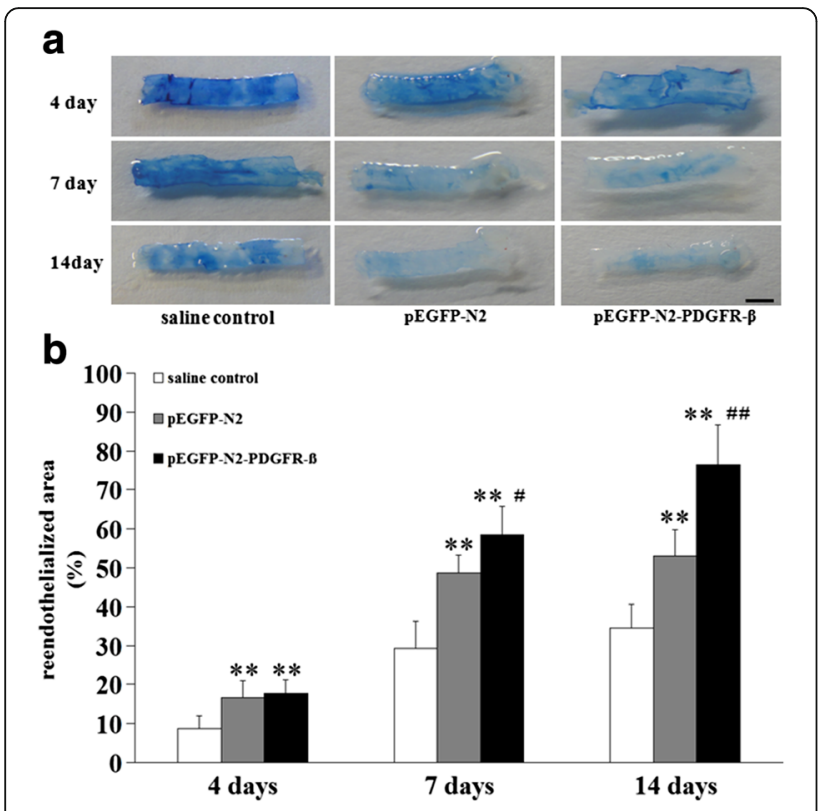

Fig. 5 Reendothelialization of injured carotid arteries is promoted by EPC transplantation and further enhanced by transplantation with EPCS overexpressing PDGFR- $\beta$. a Representative images of reendothelialization at days 4, 7, and 14 after wire-mediated carotid artery injury in the saline control, pEGFP-N2, and pEGFP-N2-PDGFR- $\beta$ groups. b Quantification of Evans blue staining showed that PDGFR- $\beta$ overexpression accelerated reendothelialization at days 7 and 14 after wire-mediated carotid artery injury, while no difference was observed at day $4 .{ }^{*} P<0.01$ vs. saline control group; ${ }^{*} P<0.05$ vs. pEGFP-N2 group; ${ }^{\# \#} P<0.01$ vs. pEGFP-N2 group ( $n=8$ per study group). Scale bar $=1 \mathrm{~mm}$

\section{Transplantation of EPCs overexpressing PDGFR- $\beta$ attenu-} ated neointima formation

The effect of transplantation of EPCs overexpressing PDGFR- $\beta$ on neointima formation was evaluated by HE staining at 14 days after the carotid injury. At day 14 , a significant decrease $(P<0.05)$ in $\mathrm{NI} / \mathrm{M}$ ratio was noted in the pEGFP-N2-PDGFR- $\beta$-EPCs group (0.29 $\pm 0.07)$ as compared with that in the pEGFP-N2-EPCs group $(0.43 \pm 0.08$; Fig. $6 \mathrm{a}, \mathrm{b})$ and in the saline control group $(0.73 \pm 0.13, p<0.01)$. Our results indicate that the transplantation of EPCs overexpressing PDGFR- $\beta$ can inhibit neointima formation in the early phase after carotid artery injury.

\section{Transplantation of EPCs overexpressing PDGFR- $\beta$ in- creased intima cells apoptosis}

We next examined the effects of transplantation of EPCs overexpressing PDGFR- $\beta$ on intima cells apoptosis/necrosis by TUNEL staining (Fig. 7a, b and c). After 7 days of the carotid injury, the TUNEL-labeling index was significantly greater in the pEGFP-N2-PDGFR- $\beta$-EPCs group $(36.45 \pm 5.83)$ than in the pEGFP-N2-EPCs group $(24.45 \pm 6.08, p<0.01$, Fig. $7 d)$, indicating increased intima cell apoptosis was associated with PDGFR- $\beta$ overexpression.

\section{Effects of EPCs overexpressing PDGFR- $\beta$ on PDGF-BB- induced VSMC migration}

To examine the effects of PDGF-BB-induced VSMCs, co-culture Transwell system was used. The main effect of concentration $(\mathrm{F}=271.088, \quad P<0.01)$ and group $(\mathrm{F}=335.35, P<0.01)$, as well as their interaction $(\mathrm{F}=34.699, P<0.01)$, were all significant. The maximum migration induced by recombinant PDGF$\mathrm{BB}$ occurred at $20 \mathrm{ng} / \mathrm{mL}$ in the control group and pEGFP-N2-PDGFR- $\beta$ groups and at $60 \mathrm{ng} / \mathrm{mL}$ in the pEGFP-N2 group (Fig. 8b). Interestingly, in the pEGFPN2-PDGFR- $\beta$ group, VSMCs migration decreased significantly with increase in PDGF-BB concentration $(P<0.01)$ (Fig. 8a, b), indicating that PDGF-BB-induced VSMCs migration is attenuated by EPCs overexpressing PDGFR- $\beta$.

\section{Effects of EPCs overexpressing PDGFR- $\beta$ on PDGF-BB treatments reduced VSMCs apoptosis}

VSMCs apoptosis plays an important role in vascular remodeling. We then used the in situ Cell Death Detection Kit to examine the effects of PDGF-BB treatments reduced VSMCs apoptosis. The main effects of concentration $(\mathrm{F}=17.798, \quad P<0.01)$ and group $(\mathrm{F}=74.428, P<0.01)$, as well as their interaction $(F=10.376, P<0.01)$, were all significant. The minimum TUNEL-labeling index was at $20 \mathrm{ng} / \mathrm{mL}$ PDGF-BB in the control group and at $80 \mathrm{ng} / \mathrm{mL}$ PDGF-BB in the pEGFP-N2 group respectively (Fig. 9a). In contrast, in the pEGFP-N2-PDGFR- $\beta$ group, TUNEL-labeling index remained unchanged under different concentrations of PDGF-BB $(P>0.05)$ (Fig. 9b), indicating that PDGF-BB treatments reduced VSMCs apoptosis is attenuated by EPCs overexpressing PDGFR- $\beta$.

\section{Discussion}

In this study, we found that transplantation of EPCs overexpressing PDGFR- $\beta$ significantly promoted reendothelialization in the early phase after carotid artery injury in mice. Additionally, EPCs overexpressing PDGFR- $\beta$ inhibited neointima formation via increasing apoptosis and suppressing proliferation of VSMCs. The cause of limited neointima formation might be that homed EPCs overexpressing PDGFR- $\beta$ can compete for the locally produced PDGF-BB which is a result of injured arteries with the VSMCs, therefore inhibiting the local VSMC migration, proliferation, antiapoptotic function, and reduced neointima formation. This assumption then confirmed by our experimental results in vitro. This study first reported that transplantation of genetically modified 


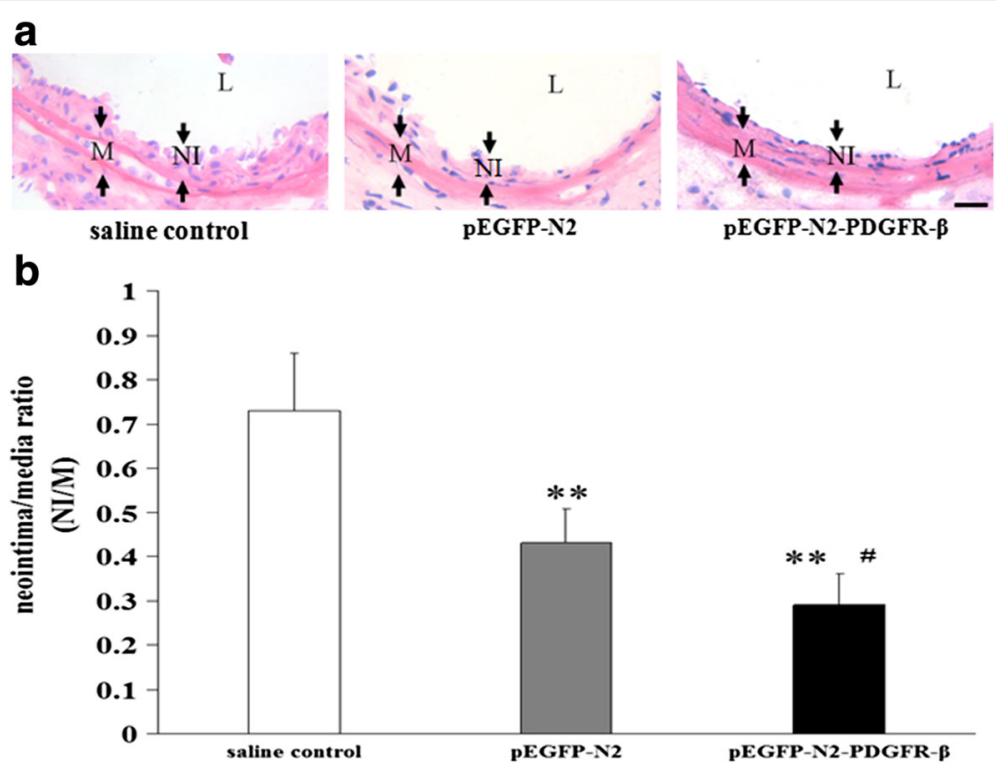

Fig. 6 Transplantation of EPCS overexpressing PDGFR- $\beta$ inhibited neointima formation at day 14 after carotid artery injury. a Representative photos of carotid artery were stained with HE. $\mathbf{b}$ Neointima/media ratios in the injured vessels of the saline-treated, pEGFP-N2-EPCs-transplanted, and pEGFP-N2-PDGFR- $\beta$-EPCs-transplanted groups. ${ }^{* *} P<0.01$ vs. saline control group; ${ }^{\#} P<0.05$ vs.pEGFP-N2-EPCs group ( $n=12$ per study group). L, lumen; M, media; NI, neointima. Scale bar $=50 \mu \mathrm{m}$

EPC can have a combined effect of both amplifying the reendothelialization capacity of EPCs and inhibiting neointima formation so as to facilitate better inhibition of adverse remodeling after vascular injury.

EPCs can differentiate into mature ECs in vivo and therefore play an important role in vascular endothelial repair and angiogenesis in the ischemic tissues [17, 20-23].
The number and biological function of the body's circulating EPCs largely reflect the ability of vascular repair and microvascular reconstruction of the ischemic tissues $[6,8,24,25]$. In certain diseases such as diabetes, coronary heart disease, and chronic renal failure, the number and/or biological function of the circulating EPCs decreases significantly, causing and/or facilitating

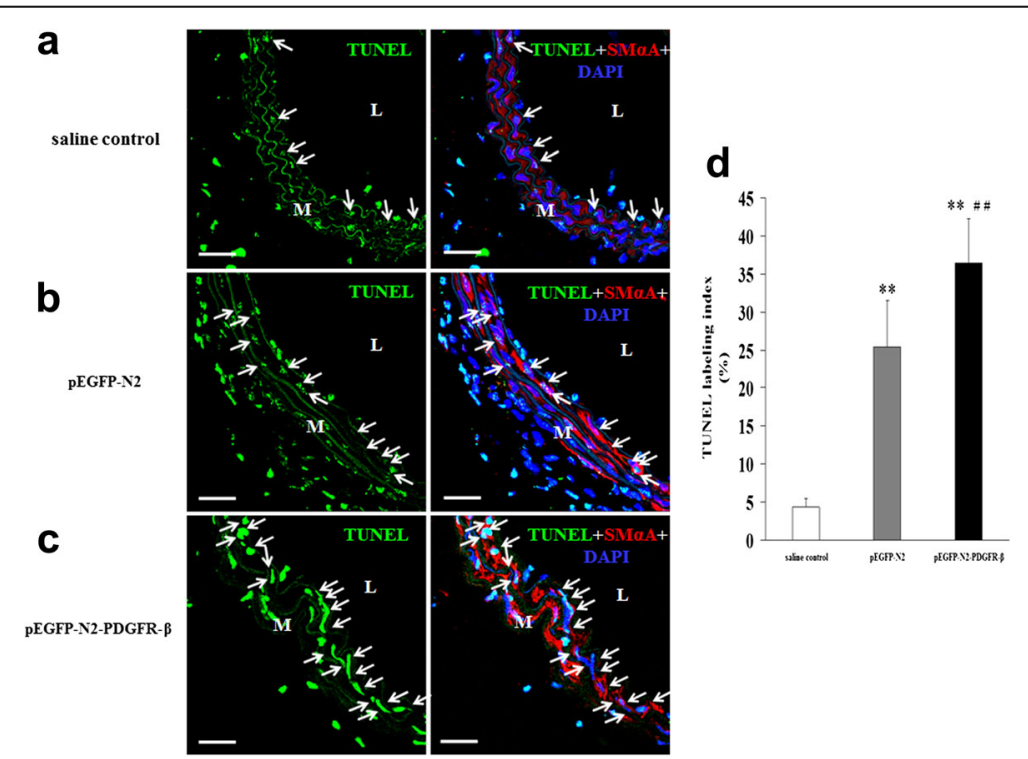

Fig. 7 Transplantation of EPCs overexpressing PDGFR- $\beta$ induces apoptosis of medial cells (VSMCs). Fluorescent TUNEL staining in injured arteries of the $\mathbf{a}$ saline control group, $\mathbf{b}$ pEGFP-N2-EPCs group, and $\mathbf{c}$ pEGFP-N2-PDGFR- $\beta$-EPCs group. Arrows indicate TUNEL-positive cells (green). Red: VSMCs

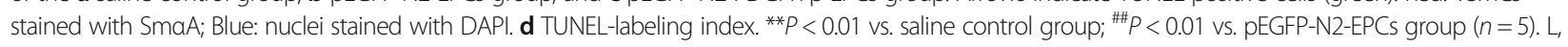
lumen; $\mathrm{M}$, media. Scale bar $=50 \mu \mathrm{m}$ 


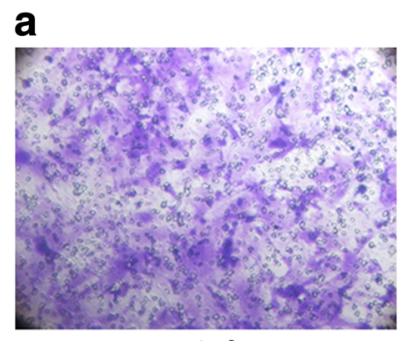

b

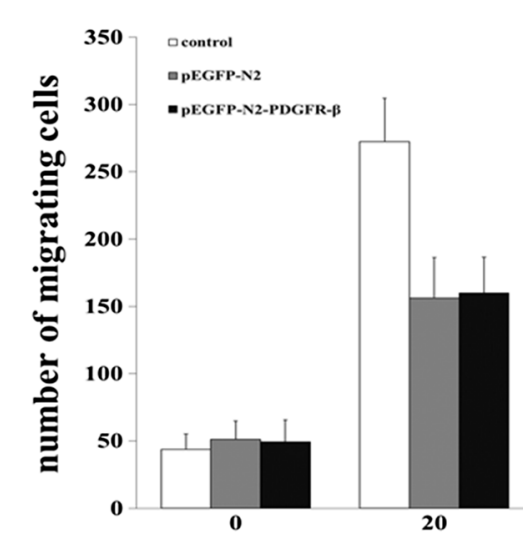

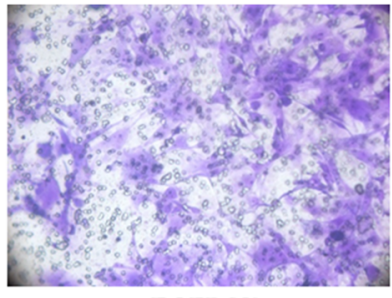

pEGFP-N2

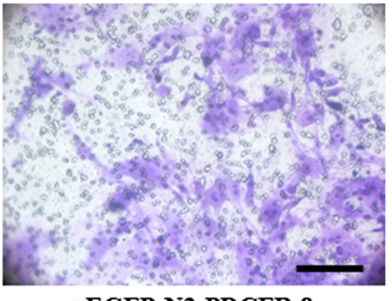

PEGFP-N2-PDGFR- $\beta$

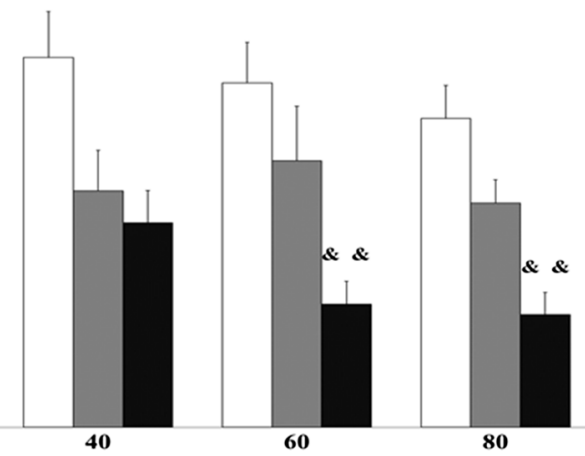

PDGF-BB ( ng/ml )

Fig. 8 Effects of PDGF-BB induced VSMC migration. a Representative images from VSMCs migration by recombinant PDGF-BB occurred at 60 ng/ $\mathrm{mL}$. b VSMC migration was examined by the co-culture migration assay.\&\& $P<0.01$ vs. pEGFP-N2-PDGFR- $\beta$ cells under 0 ng/mL PDGF-BB stimulation. Scale bar $=100 \mu \mathrm{m}$

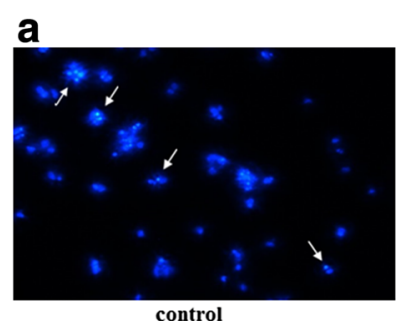

control

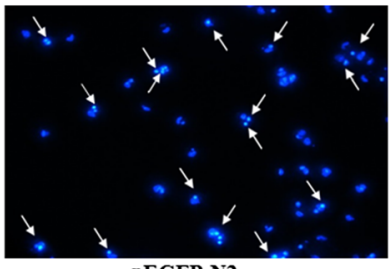

pEGFP-N2

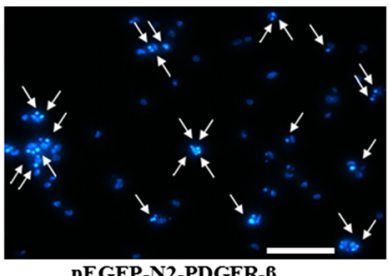

pEGFP-N2-PDGFR- $\beta$

\section{b}

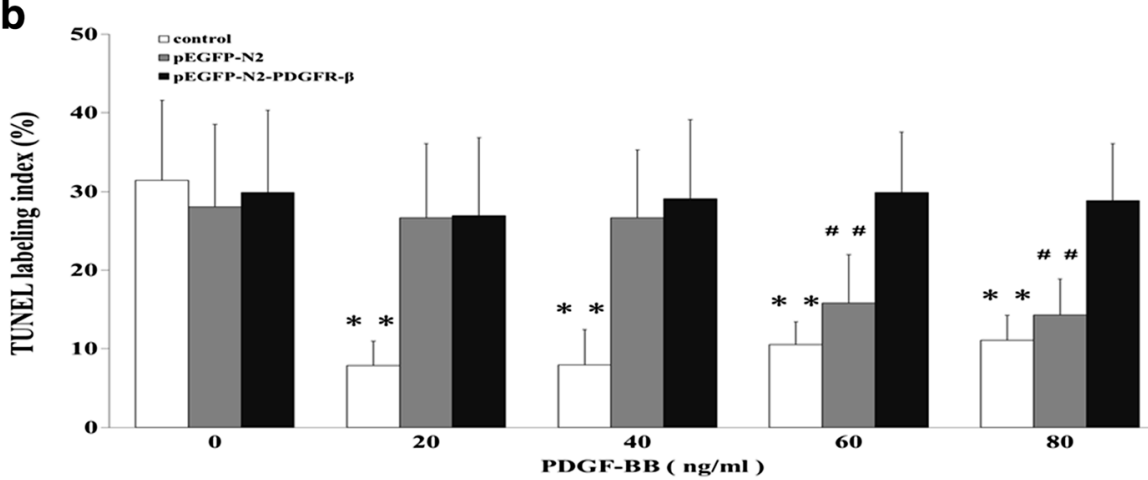

Fig. 9 Effects of PDGF-BB treatments reduced VSMC apoptosis. a Representative images from VSMCs apoptosis when recombinant PDGF-BB occurred at $80 \mathrm{ng} / \mathrm{mL}$. Arrows indicate TUNEL-positive cells (green). b VSMC apoptosis was examined by using the in situ Cell Death Detection Kit. ${ }^{* *} P<0.01$ vs. Control cells under 0 ng/mL PDGF-BB stimulation. ${ }^{\#} P<0.01$ vs. pEGFP-N2 cells under 0 ng/mL PDGF-BB stimulation. 
the occurrence and development of these diseases $[6,8$, 24-26]. Even under the normal physiological condition, in case of acute vascular injury or acute tissue ischemia (e.g., vascular endothelial damage due to a surgery), shorttime blocking of the blood flow to organs, and shock leading to systemic perfusion, the number of circulating EPCs in the body are insufficient for the repair of the damaged vascular endothelium, for remodeling of the microvascular network, and for angiogenesis [17, 21, 27-29].

Previous studies have confirmed that EPC mobilization or transplantation to increase the number of circulating EPCs can promote the repair of damaged vascular endothelium [17, 21, 22, 30-36]. Transplantation of EPCs, whose biological functions have been improved by genetic modification or cytokine induction, could further enhance the repair of damaged blood vessels, as observed in some previous studies [37, 38]. In addition, a few studies reported that applying the receptor-ligand interaction mechanism to promote directional chemotaxis of EPCs could increase the number of EPCs homing to the damaged blood vessels [16, 38-40]. Both these approaches, acting on a single link, can achieve a certain effect, but not the desired effect. Presently, the homing, proliferation, and differentiation of circulating EPCs as well as the interaction of these cells with the surrounding tissue cells remain to be investigated.

Recent data have shown that remote ischaemic preconditioning reduced the incidence of periprocedural myocardial infarction following PCI [41]. Vascular interventional therapy as well as several other factors such as blood flow stress can lead to vascular intima damage, which can result in adhesion and aggregation of a large number of platelets in the intimal lesion. The adhesion of platelets releases a large amount of PDGF. Meanwhile, vascular intimal injury induces transformation of local VSMCs from contractile cells to secretory cells, leading to synthesis and secretion of a large amount of PDGF $[42,43]$. PDGF exerts biological activity through the paracrine and/or autocrine glands. The PDGF family, especially PDGF-BB, is closely involved with the restenosis of the target vessels after PCI, atherosclerosis, and other vascular intimal proliferative diseases. Under normal physiological conditions, the normal artery walls have very low PDGF-BB expression level, but the PDGF-BB expression level in the target vascular tissue after PCI or in atherosclerotic vascular lesions is increased [44-46].

The local production and release of PDGF-BB exert its function in an autocrine and/or paracrine manner on the local VSMCs after vascular injury. It promotes proliferation, migration, and phenotype transformation of VSMCs [47]. In addition, it promotes postoperative restenosis after $\mathrm{PCI}$ and the formation of atherosclerosis plate $[14,48]$. A recent study has also shown that PDGF-
$\mathrm{BB}$ can induce proliferation, migration, and angiogenesis of EPCs over-expressing PDGFR- $\beta$ receptor [16].

PDGF-BB functions mainly by acting on its specific receptor. PDGFR is a transmembrane glycoprotein possessing protein tyrosine kinase activity composed of two subunits, alpha and beta. The beta subunit PDGFR- $\beta$ plays an important role in the occurrence and development of vascular intimal proliferative diseases induced by PDGF-BB [14, 48]. PDGFR- $\beta$-specific receptor blockers can effectively inhibit neointimal hyperplasia induced by PDGF-BB and reduce the degree of stenosis after vascular injury $[49,50]$.

Our result is consistent with previous report that the local expression and release of PDGF-BB increased during the acute period after carotid artery injury in mice and that this increase was sustained for a long time (approximately 2 weeks) [51, 52]. After transplantation of EPCs overexpressing PDGFR- $\beta$ or EPCs with blank plasmid, we found that the number of EPCs homing to the injured arteries was significantly higher in the PDGFR- $\beta$ overexpression group than in the PDGFR- $\beta$ nonoverexpression group (blank plasmid-transfected EPCs group). Evans Blue staining revealed that the reendothelialization area of injured carotid arteries was significantly higher in the PDGFR- $\beta$ overexpression group than in the PDGFR- $\beta$ non-overexpression group at both day 7 and day 14 and improved reendothelialization was more dramatic at day 14 compared to day 7 .

Reendothelialization at sites of spontaneous or iatrogenic disruption has classically been thought to be a result from the migration and proliferation of ECs from viable endothelium adjacent to the sites of injury. Circulating EPCs as optimal candidates in cell-based therapies for vascular diseases has been well documented in contributing to the maintenance of endothelial integrity, function, and regeneration of injured endothelium [7-10]. The number, migratory capacity, and proliferative capacity of circulating EPCs are the main factors determine their ability to home to and incorporate into sites of reendothelialization. Our previous study has shown that a stably high expression of PDGFR- $\beta$ of EPCs can be achieved by transfecting EPCs with pEGFP-N2-PDGFR- $\beta$. The stimulus of exogenous PDGF-BB can significantly enhance the capability of proliferation, migration, and angiogenesis in EPCs overexpressing PDGFR- $\beta$ in vitro [16]. These could explain why both the number of EPCs homing to the injured arteries and the reendothelialization area of injured carotid arteries were significantly higher in the PDGFR- $\beta$ overexpression group than in the PDGFR- $\beta$ non-overexpression group.

We further asked whether increased reendothelialization has an impact on neointima formation. We performed $\mathrm{HE}$ staining and found the inhibition of neointima formation at day 14 after arterial injury in the 
PDGFR- $\beta$ overexpression group. This result suggests that PDGFR- $\beta$ mediated reendothelialization is reversely correlated with neointima formation during vascular regeneration at the injury site. To seek the cause of decreased neointima formation, we further performed TUNEL staining to evaluate cell apoptosis to analyze inhibition of neointimal hyperplasia by transplanted EPCs overexpressing PDGFR- $\beta$ after arterial injury. We found that transplanted EPCs with PDGFR- $\beta$ overexpression can promote local VSMCs apoptosis in the injured carotid artery in mice at day 7 after cell transplantation. Then, we established the VSMC/EPC co-culture system in vitro. Our data shown that PDGF-BB-induced VSMC migration and PDGF-BB treatments VSMC antiapoptotic function is attenuated by EPCs overexpressing PDGFR- $\beta$ competitively consume the PDGF-BB.

There are some limitations in our paper: First, our observations are based on a relatively simple animal model (young and healthy mice), and thus, the study conclusions may be limited to non-atherosclerotic arteries. Second, we did not observe the enhancing effects of the endogenous PDGF-BB, released locally by the injured carotid arteries in mice, on the recruitment of EPCs over-expressing PDGFR- $\beta$. The above-mentioned limitations would be addressed in our future studies.

\section{Conclusions}

Our present study suggests that the interaction between the transplanted EPCs overexpressing PDGFR- $\beta$ and the PDGF-BB expressed and released locally by the injured carotid arteries of mice can promote homing of EPCs overexpressing PDGFR- $\beta$ to the injured arteries, accelerate reendothelialization of the injured artery, and inhibit neointimal proliferation of the injured arteries after vascular injury. In addition, overexpression of PDGFR- $\beta$ in the recruited EPCs can competitively consume the PDGF-BB generated locally by the injured arteries, promoting proliferation, migration, and anti-apoptosis of vascular VSMCs, which in turn can strengthen the inhibition of neointimal hyperplasia induced after vascular injury. Thus, our results suggest that the transplantation of EPCs overexpressing PDGFR- $\beta$ can be used as a novel therapeutic approach for the treatment of vascular injury diseases.

\footnotetext{
Abbreviations

ANOVA: Analysis of variance; DMEM/F-12: Dulbecco's modified eagle medium: nutrient mixture F-12; ECs: Endothelial cells; EGFP: Enhanced green fluorescent protein; EPCs: Endothelial progenitor cells; FCS: Fetal calf serum; HE: Hematoxylin and eosin; HPFs: High-power fields; IP: lintraperitoneal; NI/ M: Neointimal /media; OCT: Optimal cutting temperature; PDGFR: Plateletderived growth factor receptor; PO: Per os; PVDF: Polyvinylidene fluoride; RTPCR: Reverse transcription-polymerase chain reaction; SMaA: Smooth muscle a-actin; TUNEL: Transferase dUTP nick-end labeling; VSMCs: Vascular smooth muscle cells
}

\section{Acknowledgements}

We thank Meng-yang Deng and Hua-li Kang for excellent technical help.

\section{Funding}

This work was supported by grants from the National Natural Science Foundation of China (No. 30900620, No. 81100112 and No. 81300153) and grants from the Natural Science Fund Project of Hubei Province (2014 CFA066).

\section{Availability of data and materials}

The datasets during and/or analysed during the current study available from the corresponding author on reasonable request.

\section{Authors' contributions}

HW performed the experiments and draft the manuscript, YY performed the animal experiments and draft the manuscript. XZ carried out the cell culture, participated in the immunofluorescence assay, JY participated in the cell culture, QW carried out the animal model and EPC transplantation. WL participated in the design of the study and performed the statistical analysis. KC participated in the statistical analysis. $\mathrm{HH}$ conceived of the study, participated in its design and helped th draft the manuscript. SD conceived of the study, and participated in its design and coordination and helped to draft the manuscript. All authors read and approved the final manuscript.

\section{Competing interests}

The authors declare that they have no competing interests.

\section{Consent for publication}

Not applicable.

\section{Ethics approval and consent to participate}

All procedures were performed in compliance with the Ethic Committee of Third Military Medical University and the National Institute of Health Guide for the Care and Use of Laboratory. Experimental protocols were approved by the research ethics committee of the Third Military Medical University.

\section{Author details}

${ }^{1}$ Cadre Ward Two, Wuhan General Hospital of Guangzhou Military Command, Wuhan 430070, China. ${ }^{2}$ Intensive Care Unit, The sixth people's hospital of Chongqing, Nan'an District, Chongqing 400060, China. ${ }^{3}$ Clinic center, Shenzhen Hornetcorn Biotechnology Company, Ltd, Shenzhen 518400, China. ${ }^{4}$ Institute of Cardiovascular Science, Xingiao Hospital, Third Military Medical University, Chongqing 400037, China. ${ }^{5}$ Institute of Cardiovascular Science, Wuhan General Hospital of Guangzhou Military Command, Wuhan 430070, China.

Received: 29 March 2016 Accepted: 26 August 2016

Published online: 13 September 2016

\section{References}

1. Kipshidze N, Dangas G, Tsapenko M, Moses J, Leon MB, Kutryk M, Serruys P. Role of the endothelium in modulating neointimal formation: vasculoprotective approaches to attenuate restenosis after percutaneous coronary interventions. J Am Coll Cardiol. 2004;44(4):733-9.

2. Ong AT, McFadden EP, Regar E, de Jaegere PP, van Domburg RT, Serruys PW. Late angiographic stent thrombosis (LAST) events with drug-eluting stents. J Am Coll Cardiol. 2005:45(12):2088-92.

3. Hutter R, Carrick FE, Valdiviezo C, Wolinsky C, Rudge JS, Wiegand SJ, Fuster $V$, Badimon JJ, Sauter BV. Vascular endothelial growth factor regulates reendothelialization and neointima formation in a mouse model of arterial injury. Circulation. 2004;1 10(16):2430-5.

4. Gulati R, Jevremovic D, Peterson TE, Witt TA, Kleppe LS, Mueske CS, Lerman A, Vile RG, Simari RD. Autologous culture-modified mononuclear cells confer vascular protection after arterial injury. Circulation. 2003;108(12):1520-6.

5. Griese DP, Ehsan A, Melo LG, Kong D, Zhang L, Mann MJ, Pratt RE, Mulligan RC, Dzau VJ. Isolation and transplantation of autologous circulating endothelial cells into denuded vessels and prosthetic grafts: implications for cell-based vascular therapy. Circulation. 2003:108(21):2710-5.

6. Werner N, Kosiol S, Schiegl T, Ahlers P, Walenta K, Link A, Bohm M, Nickenig $\mathrm{G}$. Circulating endothelial progenitor cells and cardiovascular outcomes. N Engl J Med. 2005;353(10):999-1007. 
7. Caporali A, Pani E, Horrevoets AJ, Kraenkel N, Oikawa A, Sala-Newby GB, Meloni M, Cristofaro B, Graiani G, Leroyer AS, et al. Neurotrophin p75 receptor (p75NTR) promotes endothelial cell apoptosis and inhibits angiogenesis: implications for diabetes-induced impaired neovascularization in ischemic limb muscles. Circ Res. 2008;103(2):e15-26.

8. Giannotti G, Doerries C, Mocharla PS, Mueller MF, Bahlmann FH, Horvath T, Jiang H, Sorrentino SA, Steenken N, Manes C, et al. Impaired endothelial repair capacity of early endothelial progenitor cells in prehypertension: relation to endothelial dysfunction. Hypertension. 2010;55(6):1389-97.

9. Kawabe-Yako R, li M, Masuo O, Asahara T, Itakura T. Cilostazol activates function of bone marrow-derived endothelial progenitor cell for re-endothelialization in a carotid balloon injury model. PLoS One. 2011;6(9):e24646.

10. Piatkowski A, Grieb G, Simons D, Bernhagen J, van der Hulst RR. Endothelial progenitor cells-potential new avenues to improve neoangiogenesis and reendothelialization. Int Rev Cell Mol Biol. 2013;306:43-81.

11. Leveen P, Pekny M, Gebre-Medhin S, Swolin B, Larsson E, Betsholtz C. Mice deficient for PDGF B show renal, cardiovascular, and hematological abnormalities. Genes Dev. 1994;8(16):1875-87.

12. Siow RC, Churchman AT. Adventitial growth factor signalling and vascular remodelling: potential of perivascular gene transfer from the outside-in. Cardiovasc Res. 2007;75(4):659-68,

13. Ferns GA, Raines EW, Sprugel KH, Motani AS, Reidy MA, Ross R. Inhibition of neointimal smooth muscle accumulation after angioplasty by an antibody to PDGF. Science. 1991;253(5024):1129-32.

14. Deguchi J, Namba T, Hamada H, Nakaoka T, Abe J, Sato O, Miyata T, Makuuchi M, Kurokawa K, Takuwa Y. Targeting endogenous plateletderived growth factor B-chain by adenovirus-mediated gene transfer potently inhibits in vivo smooth muscle proliferation after arterial injury. Gene Ther. 1999;6(6):956-65.

15. Levitzki A. PDGF receptor kinase inhibitors for the treatment of restenosis. Cardiovasc Res. 2005;65(3):581-6.

16. Wang H, Yin Y, Li W, Zhao X, Yu Y, Zhu J, Qin Z, Wang Q, Wang K, Lu W, et al. Over-expression of PDGFR-beta promotes PDGF-induced proliferation, migration, and angiogenesis of EPCs through PI3K/Akt signaling pathway. PLoS One. 2012;7(2):e30503.

17. Zhao X, Huang L, Yin Y, Fang Y, Zhou Y. Autologous endothelial progenitor cells transplantation promoting endothelial recovery in mice. Trans int. 2007;20(8):712-21.

18. Wang $H$, Cai KY, Li W, Huang $H$. Sphingosine-1-Phosphate Induces the Migration and Angiogenesis of Epcs Through the Akt Signaling Pathway via Sphingosine-1-Phosphate Receptor 3/Platelet-Derived Growth Factor Receptor-beta. Cell molecular bio letters. 2015;20(4):597-611.

19. Yin $Y$, Zhao X, Fang Y, Huang L. Carotid artery wire injury mouse model with a nonmicrosurgical procedure. Vascular. 2010;18(4):221-6.

20. Asahara T, Murohara T, Sullivan A, Silver M, VanderZee R, Li T, Witzenbichler B, Schatteman G, Isner JM. Isolation of putative progenitor endothelial cells for angiogenesis. Science. 1997;275(5302):964-7.

21. Werner N, Junk S, Laufs U, Link A, Walenta K, Bohm M, Nickenig G. Intravenous transfusion of endothelial progenitor cells reduces neointima formation after vascular injury. Circ Res. 2003;93(2):e17-24.

22. Chen L, Wu F, Xia WH, Zhang YY, Xu SY, Cheng F, Liu X, Zhang XY Wang SM, Tao J. CXCR4 gene transfer contributes to in vivo reendothelialization capacity of endothelial progenitor cells. Cardiovasc Res. 2010;88(3):462-70.

23. Lee SH, Lee JH, Yoo SY, Hur J, Kim HS, Kwon SM. Hypoxia inhibits cellular senescence to restore the therapeutic potential of old human endothelial progenitor cells via the hypoxia-inducible factor-1alpha-TWIST-p21 axis. Arterioscler Thromb Vasc Biol. 2013;33(10):2407-14.

24. Sung SH, Wu TC, Chen JS, Chen YH, Huang PH, Lin SJ, Shih CC, Chen JW. Reduced number and impaired function of circulating endothelial progenitor cells in patients with abdominal aortic aneurysm. Int J Cardiol. 2013:168(2):1070-7.

25. Yamagishi S, Maeda S, Ueda S, Ishibashi Y, Matsui T. Serum pigment epithelium-derived factor levels are independently associated with decreased number of circulating endothelial progenitor cells in healthy non-smokers. Int J Cardiol. 2012;158(2):310-2.

26. Pelliccia F, Pasceri V, Cianfrocca C, Vitale C, Speciale G, Gaudio C, Rosano GM, Mercuro G. Angiotensin II receptor antagonism with telmisartan increases number of endothelial progenitor cells in normotensive patients with coronary artery disease: a randomized, double-blind, placebocontrolled study. Atherosclerosis. 2010;210(2):510-5.
27. Werner N, Wassmann S, Ahlers P, Schiegl T, Kosiol S, Link A, Walenta K, Nickenig G. Endothelial progenitor cells correlate with endothelial function in patients with coronary artery disease. Basic Res Cardiol. 2007;102(6):565-71.

28. Spadaccio C, Pollari F, Casacalenda A, Alfano G, Genovese J, Covino E, Chello M. Atorvastatin increases the number of endothelial progenitor cells after cardiac surgery: a randomized control study. J Cardiovasc Pharmacol. 2010;55(1):30-8.

29. Zhang XY, Su C, Cao Z, Xu SY, Xia WH, Xie WL, Chen L, Yu BB, Zhang B, Wang $Y$, et al. CXCR7 upregulation is required for early endothelial progenitor cell-mediated endothelial repair in patients with hypertension. Hypertension. 2014;63(2):383-9.

30. Yu J, Wang Q, Wang H, Lu W, Li W, Qin Z, Huang L. Activation of liver X receptor enhances the proliferation and migration of endothelial progenitor cells and promotes vascular repair through PI3K/Akt/eNOS signaling pathway activation. Vasc Pharmacol. 2014;62(3):150-61.

31. Wang $\mathrm{CH}$, Lee MF, Yang NI, Mei HF, Lin SY, Cherng WC. Bone marrow rejuvenation accelerates re-endothelialization and attenuates intimal hyperplasia after vascular injury in aging mice. Circ j: official j Japanese Circ Soc. 2013:77(12):3045-53.

32. Yu Y, Gao Y, Qin J, Kuang CY, Song MB, Yu SY, Cui B, Chen JF, Huang L. CCN1 promotes the differentiation of endothelial progenitor cells and reendothelialization in the early phase after vascular injury. Basic Res Cardiol. 2010;105(6):713-24.

33. Ikesue M, Matsui Y, Ohta D, Danzaki K, Ito K, Kanayama M, Kurotaki D, Morimoto J, Kojima T, Tsutsui H, et al. Syndecan-4 deficiency limits neointimal formation after vascular injury by regulating vascular smooth muscle cell proliferation and vascular progenitor cell mobilization. Arterioscler Thromb Vasc Biol. 2011:31(5):1066-74.

34. Wang Z, Moran E, Ding L, Cheng R, Xu X, Ma JX. PPARalpha regulates mobilization and homing of endothelial progenitor cells through the HIF1alpha/SDF-1 pathway. Invest Ophthalmol Vis Sci. 2014;55(6):3820-32.

35. Kong D, Melo LG, Gnecchi M, Zhang L, Mostoslavsky G, Liew CC, Pratt RE, Dzau VJ. Cytokine-induced mobilization of circulating endothelial progenitor cells enhances repair of injured arteries. Circulation. 2004; 110(14):2039-46.

36. Iwakura A, Luedemann C, Shastry S, Hanley A, Kearney M, Aikawa R, Isner JM, Asahara T, Losordo DW. Estrogen-mediated, endothelial nitric oxide synthase-dependent mobilization of bone marrow-derived endothelial progenitor cells contributes to reendothelialization after arterial injury. Circulation. 2003;108(25):3115-21.

37. Yamauchi A, Kawabe J, Kabara M, Matsuki M, Asanome A, Aonuma T, Ohta H, Takehara N, Kitagawa T, Hasebe N. Apurinic/apyrimidinic endonucelase 1 maintains adhesion of endothelial progenitor cells and reduces neointima formation. Am J Physiol Heart Circ Physiol. 2013; 305(8):H1158-67.

38. Li D, Yan D, Liu W, Li M, Yu J, Li Y, Qu Z, Ruan Q. Foxc2 overexpression enhances benefit of endothelial progenitor cells for inhibiting neointimal formation by promoting CXCR4-dependent homing. J Vasc Surg. 2011;53(6): 1668-78.

39. Hristov M, Zernecke A, Bidzhekov K, Liehn EA, Shagdarsuren E, Ludwig A, Weber C. Importance of CXC chemokine receptor 2 in the homing of human peripheral blood endothelial progenitor cells to sites of arterial injury. Circ Res. 2007;100(4):590-7.

40. Hristov M, Erl W, Weber PC. Endothelial progenitor cells: mobilization, differentiation, and homing. Arterioscler Thromb Vasc Biol. 2003;23(7):1185-9.

41. D'Ascenzo F, Moretti C, Omede P, Cerrato E, Cavallero E, Er F, Presutti DG, Colombo F, Crimi G, Conrotto F, et al. Cardiac remote ischaemic preconditioning reduces periprocedural myocardial infarction for patients undergoing percutaneous coronary interventions: a meta-analysis of randomised clinical trials. Eurolntervention : j EuroPCR collab Working Group Interventional Cardiol Eur Soc Cardiol. 2014;9(12):1463-71.

42. Rubin P, Williams JP, Riggs PN, Bartos S, Sarac T, Pomerantz R, Castano J, Schell M, Green RM. Cellular and molecular mechanisms of radiation inhibition of restenosis. Part I: role of the macrophage and platelet-derived growth factor. Int J Radiat Oncol Biol Phys. 1998;40(4):929-41.

43. Osherov AB, Gotha L, Cheema AN, Qiang B, Strauss BH. Proteins mediating collagen biosynthesis and accumulation in arterial repair: novel targets for anti-restenosis therapy. Cardiovasc Res. 2011:91(1):16-26.

44. Barrett TB, Benditt EP. sis (platelet-derived growth factor B chain) gene transcript levels are elevated in human atherosclerotic lesions compared to normal artery. Proc Natl Acad Sci U S A. 1987;84(4):1099-103. 
45. Tanizawa S, Ueda M, van der Loos CM, van der Wal AC, Becker AE. Expression of platelet derived growth factor $B$ chain and beta receptor in human coronary arteries after percutaneous transluminal coronary angioplasty: an immunohistochemical study. Heart. 1996;75(6):549-56.

46. Suzuki J, Baba S, Ohno I, Endoh M, Nawata J, Miura S, Yamamoto Y, Sekiguchi Y, Takita T, Ogata M, et al. Immunohistochemical analysis of platelet-derived growth factor-B expression in myocardial tissues in hypertrophic cardiomyopathy. Cardiovascular pathol: offic j S Cardiovascular Pathol. 1999;8(4):223-31.

47. Raines EW. PDGF and cardiovascular disease. Cytokine Growth Factor Rev. 2004;15(4):237-54.

48. Sirois MG, Simons M, Edelman ER. Antisense oligonucleotide inhibition of PDGFR-beta receptor subunit expression directs suppression of intimal thickening. Circulation. 1997;95(3):669-76.

49. Nabel EG, Yang Z, Liptay S, San H, Gordon D, Haudenschild CC, Nabel GJ. Recombinant platelet-derived growth factor $B$ gene expression in porcine arteries induce intimal hyperplasia in vivo. J Clin Invest. 1993;91(4):1822-9.

50. Noiseux N, Boucher CH, Cartier R, Sirois MG. Bolus endovascular PDGFR-beta antisense treatment suppressed intimal hyperplasia in a rat carotid injury model. Circulation. 2000;102(11):1330-6.

51. Uchida K, Sasahara M, Morigami N, Hazama F, Kinoshita M. Expression of platelet-derived growth factor B-chain in neointimal smooth muscle cells of balloon injured rabbit femoral arteries. Atherosclerosis. 1996;124(1):9-23.

52. Lindner V, Giachelli CM, Schwartz SM, Reidy MA. A subpopulation of smooth muscle cells in injured rat arteries expresses platelet-derived growth factor-B chain mRNA. Circ Res. 1995;76(6):951-7.

\section{Submit your next manuscript to BioMed Central} and we will help you at every step:

- We accept pre-submission inquiries

- Our selector tool helps you to find the most relevant journal

- We provide round the clock customer support

- Convenient online submission

- Thorough peer review

- Inclusion in PubMed and all major indexing services

- Maximum visibility for your research

Submit your manuscript at www.biomedcentral.com/submit

C) Biomed Central 